\title{
The Potential of Technology within the Agribusiness Industry in the Emerging Market of Ghana
}

\author{
Richard Asante $^{1 *}$, Rheeta Marjery ${ }^{2}$, Frank Boateng ${ }^{3}$ \\ ${ }^{1}$ Business Development Manager, AECI Process and Water, West Africa \\ ${ }^{2}$ Principal, Sree Pashmi Institute of Management, India \\ ${ }^{3}$ Ag. Head, Management Studies Department, UMAT, Ghana
}

\begin{abstract}
This article examines the potentials of an appropriate technology with which the Ghana Agribusiness industry can leverage to boost the living conditions of the industry dependent people, increase the sector's contribution to GDP, and equip local firms with resources to stand the international competition and to offer multinational firms information required during their globalization endeavours. This will be strategic to maximise the opportunities and manage constraints. Moreover, many business constraints exist. Some are poor technological infrastructure, institutional voids, bribery, corruption, bureaucracy, and poorly trained human capital. There was a critical examination of extant studies by several scholars and researchers related to the study's objective. The review's primary focus is to establish strong conceptual, theoretical, and empirical support for this study. These included segments that dealt with the conceptual framework review of competitive advantage and theoretical reviews of the Network Theory. Structured as the third segment is the empirical review. This entails an in-depth review of extant studies related to the three-pronged objectives, with the aim of either rejecting or accepting the underlying framework in such studies. Thematic analysis was employed to analyze the primary data collected via focus group discussion and in-depth interviews. In-depth examination of participants' responses revealed that though the majority (18), 82\% of the participants indicated the adoption of technology in the workplace, whiles a few suggested partial or near adoptions.
\end{abstract}

Keywords: Agribusiness industry, Business model innovation, Constraints, Emerging market, Opportunities, Technology.

\section{Introduction}

Critical evaluation of scholarly works on the influential role of technology in emerging markets reveals that researchers and scholars are divided in their conception of technology and its potential in an emerging market.

While some scholars associated successful entry into an emerging market with the adoption of cutting-edge technology [1], others felt weak institutions in the emerging market economy could translate the myriads of opportunities into an unprofitable venture [2].

\footnotetext{
Received: 30.06.2021

Accepted: 08.02.2022

Published on: 28.02.2022
}

Deepening the gap in understanding, some scholars [3] claimed that an uncooperative or ill-structured ecosystem (upstream and downstream environment of the business different from institutional void) within which a business is embedded could seriously impact any success made in technological frontiers.

A closer study of the theories and concepts underscoring the facilitating influence of technological innovation by a firm into the emerging market has been seriously criticized by some scholars [3] as needing modification 
given the ever-changing terrain of technological frontier and emerging market.

In effect, a corporation involved in Agribusiness with mechanized farming tools in Ghana will only achieve a competitive edge and create value in the industry if other actors such as lawmakers, land administrators, customers, neighbours, are cooperative, possesses the appropriate infrastructure and technical knowhow and overcome obstacles to the use of such mechanized farming tools or innovation. This means, the firm will not only confront the challenges of adopting modern technology, both upstream (suppliers and lawmakers) and downstream (partners), will also face challenges in technology adoption.

The purpose of the study is to conduct an empirical investigation into the important role of technology in a value-driven business process design for an emerging market. The study will discover how technologies can be employed to leverage the booming business opportunities offered by phenomenally growing emerging markets.

\section{Conceptual Framework}

The concepts which underpinned the study included competitive advantage, business model innovation and Technological innovation.

\section{Concept of Competitive Advantage}

An essential component of the successful establishment of value chain business in an emerging market is a competitive advantage. This revealed fierce competition among businesses due to the revolutionary trend of technology and globalization. Hence firms must make a concerted effort at building and maintaining requisite skills and competencies and exhibit dynamism in adapting to the new environment [4], as well as meeting the fleeting demands of customers, values, and processes [5] observed that challenges associated with competition and customer needs and tumultuous business environment can be successfully completed with the application of the conceptual framework of competitive advantage. [6] however, asserted that due to a plethora of confusing information, a strategic manager disentangles the knotty gaps, the dichotomy of opinion, and ambiguity surrounding competitive edge to orchestrate his exploiting all avenues to gain a competitive edge in an emerging market. This notion urges the review of the concept of a competitive edge.

[6] provides a succinct description of what influences competitive advantage in his notable work. The description provides insight and captures the complexity regarding the competitive advantage and the study's overall objective. [7] conceives competitive advantage and the resultant improved organizational performance as representative of the adaptive ability of an organization to its environment, underscoring the point that a business organization that succeeds in adapting to the environment it operates should be capable of matching its strength with the numerous opportunities within its environment including emerging market.

\section{Concept of Business Model Innovation}

This type of innovation is quite different from technological innovation. However, it is complementary to the 4P's of technological innovation [8]. Companies and enterprises have always followed the principle of business model because they are known to have a service or product, provide consumers with the product or service, and collect financial proceeds and profit on transactions. Business management is considered by several scholars and experts [9] as a veritable means of catalyzing experimentation and innovation associated with launching a new product or entering a new market.

Building on the works of [10], conceptualize business model innovation to underscore a situation where alternative business models can be achieved to improve the dynamism associated with a business operation. Such 
dynamism will necessitate continuous reconfiguring, fine-tuning, and refining various framework. Depicted in Figure 1 is the adapted elements within the business model innovation

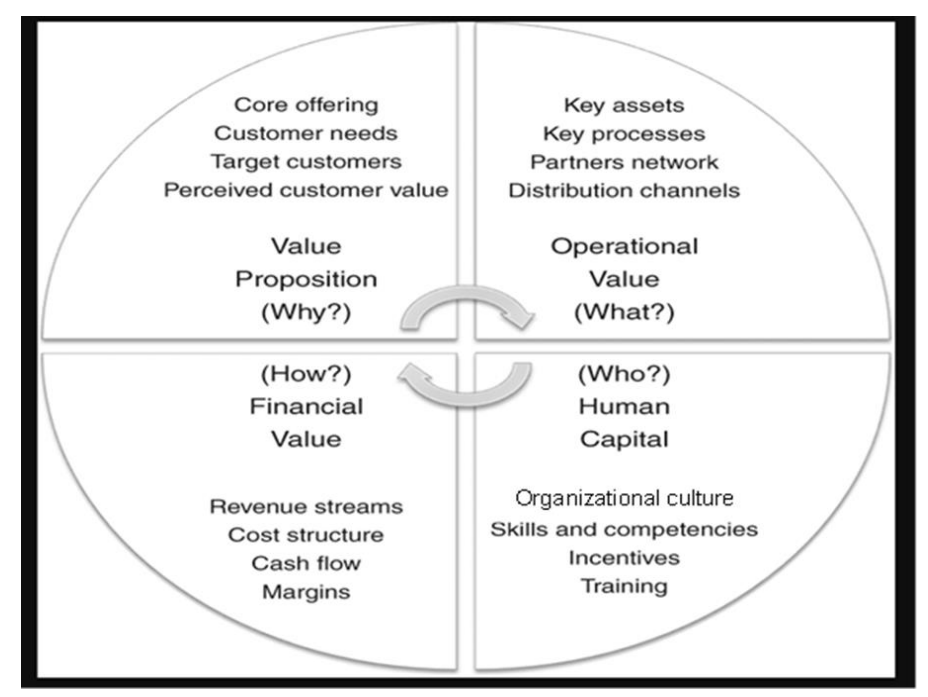

Figure 1. A conceptual framework for Business Model Innovation

Source: Adapted from Ramdani et al. (2019)

In a nutshell, building model innovation, as illustrated in this study, focuses on alternative business model innovation, an offshoot of the previous business model, and a complementary framework to technological innovation. As depicted in Figure 1, building model innovation can fast-track the introduction and sustenance of a new business enterprise in an emerging market.

\section{Concept of Technological Innovation}

Underscoring the nature of innovation, [11] provided a classic concept of technological innovation focused on fast-tracking exploitation of an emerging market by a new business organization. The focus of innovation in this sense is on technology [11]. Initially, Schumpeter's attention was on the tangible aspect of innovation, where a steelmaking entrepreneur gains entry or exploits the emerging market through an innovative approach in production processes. The entrepreneur destroys old structures and creates new ones to legitimize its presence in the emerging market through research and development $(\mathrm{R} \& \mathrm{D})$.
[12] discussed the relationship between technological and non-technological factors that can fast track generation. They predicted that the implementation of novel innovation is often lacking. [13] asserted that several innovative activities currently exist that cannot be quantified or measured using the current measurement instruments. Likewise, [14] argues that how several scholars and researchers "conceptualize, define, operationalize, and analyze 'innovation' is rooted in the past, leaving us less able to grapple with other less visible forms of innovation" (p. 11).

Hence, [15] employed a graphic and compelling term "dark innovation" far better than the common term "hidden innovation" to underscore several innovative activities that "has been ignored or are essentially 'invisible' in terms of conventional indicators" (p. 11, 434). $[14,16]$ highlighted some dark innovations as involving innovations based on design, user-related innovation, software, branding, and other intangible investment within the emerging markets such as social innovation. Critical evaluation of [14] submission necessitates defining, 
conceptualizing, and filling the literature gap regarding "dark innovation" in connection with technological innovation.

To fill the gap regarding "dark innovation" in the scope of technological innovation, especially within the framework of an emerging economy, several studies [17] have highlighted the evolving nature of technological innovation and its application within the business sector. For example, [17] posited that technological innovation is very applicable within the sphere of industries or business sectors with less $R \& D$ orientation, such as those with low-technology manufacturing, services, organizational, and marketing innovations.

Technological innovation is thus conceived, according to [17], as involving intangible aspects. Hence, [17] defined this form of technological innovation as involving "implementation of a new or significantly improved product (good or service), or process, a new marketing method or a new organizational method in business practices... or external relations" (p. 46). [17] indicated that this is the way new businesses interested in exploiting emerging markets establish their presence, economic outcomes, and performance. In this sense, the newly implemented approaches, techniques, and methods lead to the accumulation of knowledge to facilitate better performance and financial outcomes in the new terrain.

\section{Theoretical Framework}

There are several theories on using technology to create value, improve productivity, and maintain continuity of competitive advantage for an agribusiness firm venturing into an emerging market [18]. However, Network theory will be reviewed as the undergirding framework for the proposed study.

\section{Network Theory}

As an offshoot of U-Model, Network Theory considers a firm's entry into emerging markets from the perspective of interdependent partners [18]. The proponent of network theory argues that due to the complex interactions within an emerging market, it is difficult for firms to follow the sequential or incremental steps espoused by the U-model theory. Instead, prospective firms rely on resources from partners within the sector and market. [18] refer to this network as an ecosystem. The diagram in Figure 2 vividly portrays the opportunities and constraints that a prospective firm may experience when entering into an emerging market comprising several upstream and downstream partners.

A closer study of figure 2 shows that most of the literature on network theory often focuses on the first quadrant by the left with low external challenges.

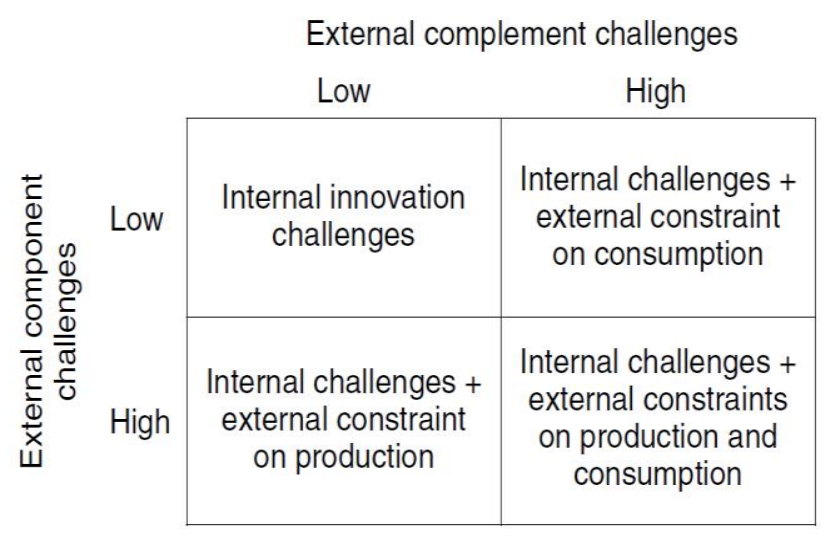

Figure 2. Impact of ecosystem challenges on a prospective investor

Source: Adner and Kapoor (2009) 
This implies that as soon as the firm overcomes its internal challenges, it can successfully enter into the merging market. However, the remaining three quadrants reveal high external component challenges and internal challenges to overcome before the firm can enter the emerging market.

\section{The Implication for the Proposed Study}

The theory underpins the focus of the study because it underscores the gap in the literature concerning the constraints a prospective firm could encounter before successful integration into the market. Initially, it was conceived that as soon as a firm overcomes the internal challenges of integrating technology as a source of value creation, it would have attained a competitive advantage. However, in [19, 20] studies, external challenges arising from interdependent partners concerning the use of appropriate technology could seriously impact any success a firm could attain even if it has overcome internal challenges within its establishment. For example, a plastic corporation only needs to device appropriate technology to produce its plastic. Suppliers, customers, and others need not worry about complementing the technology employed in the production of plastics. However, a firm such as a hotel would need its upstream (suppliers) and downstream (customers) partners to cooperate with the technologies adopted for operations; otherwise, the firm may be out of business [20].

However, the nature of challenges to be confronted by individual firms entering into emerging markets differs. To use cutting-edge technology for value creation and maintenance of a competitive edge, a firm must carefully consider the best form of technology during process design. Hence, there is a need to fill the lacuna in understanding a firm interested in agribusiness in an emerging market economy.

\section{Literature Review}

Emerging markets are very competitive and are constantly growing with new trends and technology alongside several [21]. This underscores the fact that an agribusiness investor should calculate the cost by making a novel decision on ensuring competitive advantage, increased productivity, and continuity. All of which can be done by adopting appropriate technology [22].

The review argues that there are several constraints leveled against the instrumentality of technology in the process of designing valuedriven business within an emerging market [23]. Despite these constraints, it remains a potent variable and an inextricable element for successful business ventures in the emerging market. Conceptual and theoretical frameworks were synthesized to determine whether several theories underpinning the influence of technological innovation need modification given the ever-changing terrain of technological breakthroughs.

In fulfilling the study's primary objective, the researcher seeks to retrieve firsthand information regarding African society's socioeconomic and day-to-day realities. Hence, the review contended that most studies on the facilitation of value-driven business within the emerging market environment are secondary data. It has limited studies employing primary data or empirical investigation as an approach to research.

The findings of several studies [23] revealed certain limiting factors associated with emerging markets. These include digital infrastructural constraints, shifting sand of tax law on digital technology, poor digital security, and localization. This study argues that rigorous interrogation of extant studies and empirical findings will help distill relevant information. This information helps develop the innovative approach that can override these hurdles and create a value chain and thriving enterprise in Agribusiness if used by investors.

\section{Empirical Review}

This section of the study critically examined extant literature about the study's objectives. 
Studies were examined chronologically to isolate gaps in the literature and empirical solidrical support for the present study's focus. The review in this section examined relevant studies connected with several market opportunities within emerging markets ready for exploitation by an investor or business organization alongside constraints that may limit such exploitation. The review entails rigorous interrogation of extant literature in connection with the facilitation of business operation through the application of novel technologies to meet the tenet of the 4P's of technological innovation and business model innovation in mitigating the constraints associated with value creation and maximization of profit. The empirical review also touched on the inestimable benefit of technology-savvy businesses over the traditional businesses in terms of a competitive edge as well as profit margin. Another aspect of technology-savvy businesses was also examined, especially about Corporate Social Responsibility, which is considered an essential factor in competitive advantage within an emerging market [24].

\section{The Employment of Appropriate Technology for Value Creation}

The findings of several studies basing their conception on technological innovation [25], business model innovation, and competitive advantage see novel technology and the latest breakthrough in the technological frontier as closely linked and inseparable to improved productivity and sustained competitive advantage. For example, [26] indicated that technology such as big data solutions could fast track productivity within the agricultural setting, [26] posited that with an innovative approach to product and service design through statistical software and technology such as big data statistical solution [26].

However, several other scholars and researchers [27] see the matter differently from the concept of economic theory. This school of thought focused its attention on the several limiting factors constraining technology integration in business operations within the emerging market [28]. They are concerned with the specificity regarding each technology. By specificity, they mean specific technology could be applicable in one context and nonapplicable in others [29]. Likewise, the cost and maintenance of such technology could be intimidating or counter-productive if they are inappropriate to the chosen area of application. Considering the dichotomy of opinion among scholars, technology's facilitation of new investors or prospective businesses in an emerging market is not automatic or by default. The prospective investor and business organization must approach selecting appropriate technology innovatively, considering what works best, the overhead cost of using such technology, the overall cost of production when such technology is used, and the level of profitability during the integration of such technology. This means, within the context of agribusiness, it is pertinent that a prospective investor critically examines available technologies under the probing light of the four elements of business model innovation to determine whether such implementation will yield a higher profit margin or mar the profitability of the business venture.

The prospective investor also needs to examine the cost of getting such technology overseas compared to locally made ones. This is part of the resourcefulness prospective investors need, especially the ability to use local raw material for production to minimize cost and maximize profit [30].

The new business organization should also consider the implication of political instability in several emerging economies due to fledgling democracy tainted with high-level corruption. Forestalling such constraint, [3] felt that with the presence of an enabling ecosystem, a prospective business organization could succeed, especially in developing a product or 
service with technology partners, and customers could readily adopt and access when needed. However, a gap remains on how a prospective investor could merge business model innovation with technological innovation within the sphere of agribusiness, knowing the fluidity and unstable nature of technological innovation making obsolete an appropriate technology of today within a short while [28]. Moreover, within the context of agribusiness, the success of farmers is directly proportional to the success of investors [31]. Hence, unpredictable weather conditions could also be a limiting factor in technology implementation since floods, pests, and other natural disasters could mar the successes achieved so far.

\section{Methodology}

An inestimable aspect of the research project is the systematic approach to collecting relevant information, to fill the lacuna in literature, and adequately addressing research problems [32]. To garner rich data culminating in wellvalidated and reliable findings, the method adopted should be unbiased and rigorous [33].

A critical examination of the theories undergirding the present study, comprising Network, Theory, necessitates adopting interpretivism as the research philosophy. The theoretical perspective of interpretivism revolves around making sense of subjects' subjective intention and varied meanings within a context or universe of a study, without the imposition of prior analytic groupings [34].

Interpretivism entails concerted effort by the researcher at understanding the world from the viewpoint and firsthand information retrieved from the study's participants. The findings of several studies [35] reveal that there are threepronged approaches to research projects, namely: 1) quantitative paradigm, 2) qualitative paradigm, and 3) mixed-methods combining qualitative and quantitative research paradigms. After carefully examining the three forms of research paradigms, the qualitative research paradigm is adopted for this study, given the research philosophy guiding the study. [36] Indicated that qualitativehelpfuligm helps conduct an in-depth investigation concerning the subject matter of research and enhance researchers' ability to employ case studies or multiple case studies to furnish a narrative or descriptive account of practice or design.

Qualitative research design is very suitable for the study because it facilitates efforts to gain a deeper understanding of the relevant facets for collecting well-validated information based on first-hand experience of participants void of manipulation by the researcher. [37] Indicated that, like quantitative research design, qualitative studies can also be generalized to a more significant population.

Relevant data were elicited from 22 participants. An in-depth interview was conducted with 10 management and nonmanagement staff participants. To moderate Focus Group Discussion, 12 participants were divided into three groups comprising four participants to distill relevant information related to the focus of the study.

Process managers and other professionals such as those in the R\&D and Marketing Department were interviewed. I consulted relevant sources, including peer-reviewed sources, to bridge the gaps identified at the outset of the study and retrieve valuable information to aid the resolution of research problems. Due to their successes in their respective businesses, they possess a wealth of experience in transcending limiting factors such as unpredictable market forces, weak institutions, and difficulty associated with selecting the most appropriate technology. Participants comprised 12 men and 10 women.

The majority (14) of the participants have over 8 years of working experience, 4 had over 12 years of working experience, while the remaining 4 had less than 8 years of working experience. This clearly demonstrated that this group of participants could provide rich data as far as the focus of this study is concerned. 


\section{Research Instruments/Measurements}

The proposed study will employ two powerful instruments for data collection. Structure interview guide and focus group discussions will be relevant in collecting pertinent information from participants and individual cases. Suggesting appropriate means of employing a structured interview guide, [38] indicated that an interview guide should be designed to elicit the best possible information from the participants to the end of enriching the study's findings. This means much attention will be given to the content of the interview guide.

The guide will be structured to touch on relevant issues that would fast track resolution of the three research questions. The focus will elicit important information regarding the topic under research. It will entail open-ended questions probing how firms, primarily locallyowned ones, can exploit the numerous opportunities in an emerging market using appropriate technology. The guide will also touch on how these firms overcome constraints that could have mitigated entry into emerging markets or continuity of value-creation and competitive edge.

[39] posited that the Focus Group Interview (FGI) is a highly result-oriented and credible instrument for data collection in a qualitative research approach. [39] Defined Focus Group Interview is a technique where participants are drawn from various backgrounds within the sphere of the phenomenon under study to discuss and relieve complex personal experiences, perceptions, beliefs, attitudes, and perceptions via a moderated or coordinated interaction. [40] succinctly stated that it creates an avenue where the researcher co-creates meaning with participants on the given subject, phenomenon, or topic under consideration.

As a result, stakeholders in the agribusiness would be selected for the study and interviewed and participate in focus group discussions alongside other staff within the firm. This will ensure the co-creation of meanings regarding the focus of the study.

\section{Techniques for Data analysis}

Thematic analysis will be employed for analyzing primary data collected via focus group discussion and in-depth interviews. According to [41], thematic analysis involves immersion in textual data with the sole aim of deciphering and identifying emerging trends, patterns, and themes for analysis.

In order to gather credible and reliable data, all interview and focus group discussions will be recorded with a digital recorder based on the consent of participants. Recorded interviews and discussions will be played afterward and manually transcribed to identify trends, patterns, and themes relevant to the resolution of research problems.

The themes generated will be used as a significant reference point for the analysis. In some instances, verbatim quotations from transcribed data will be reproduced to enable readers to feel the study's pulse and deepen knowledge on strategic management associated with appropriate technology, value-creation, and emerging market [23, 42].

There are various approaches to conducting thematic analysis, but the most common form followed is a six-step process:

1. Familiarization

2. Coding

3. Generating themes

4. Reviewing themes

5. Defining and naming themes

6. Writing up

\section{Results}

The primary focus of this chapter is to unravel relevant insight, trends, patterns, and themes from the elicited data for the study. In effect, this section deals with findings or outcomes of the study within the context of the transcribed data retrieved from the field. The overarching objective of the study is to conduct an empirical investigation into the critical role 
of technology in a value-driven business process design for an emerging market.

\section{Extracts and Analysis}

\section{Research Question \# 2}

In what ways can appropriate technologies be utilized during product and service design stages to mitigate these constraints and maximize the bottom line of value creation at an acceptable profit?

This question is directed towards ascertaining what appropriate technology within the context of agribusiness activities is. It is also envisaged that relevant information will be elicited regarding the processes of product and service design as a lever to mitigate the identified constraints associated with agribusiness operation within Ghana.

Adequately answering this research question requires in-depth information regarding the various technology business leaders within the Agribusiness sector in Ghana are using to maximize profit. This study segment will provide ample insight into what business leaders consider the most crucial strategy in outpacing limitations associated with the emerging market. The analysis will unearth relevant information concerning how business leaders and investors succeed in launching new products that meet the customer's taste due to the carefully orchestrated process and product design. Such a product is affordable meets customers' imagined value with minimal cost of production.

Participants' responses are presented below regarding appropriate technology to fast-track the creation of value within the agribusiness sector in Ghana. Responses are summarized in the excerpt below. The effort has been made to adequately represent participants' knowledge, understanding, and perspectives in the excerpts and analysis.

In response to the question that could be termed appropriate technology in agribusiness, participants' responses revealed that the majority (18) are fully aware of what constitutes appropriate technology. While some are already using it, others are yet to integrate it into their business operations fully. Participants' responses are summarized in the excerpts below: In my perspective, appropriate technology is any type of technology developed to transcend constraints associated with an agribusiness organization's production and economic growth.

Management staff with 9 years of working experience.

With my experience in agribusiness, I think appropriate technology should not only be concerned about boosting the economic advantage of an organization, but designers of such technology should also be concerned about the welfare of the people around whether the technology will not destroy natural habitat. This reminds me of some pesticides or machinery that could harm employees and customers alike.

Management staff with 14 years of working experience.

Appropriate technology is not only about the organization; it is also about the community. The technology should be helpful in the resolution of recurring problems limiting growth in the community, especially if it is an agriculturally based society.

Gleaned from Focus Group No. 3.

As captured in the excerpts above, a perusal of participants' responses revealed that appropriate technology is created out of necessity borne from ingenuity. The right technology becomes relevant when it resolves a recurring or suddenly developed constraint or challenge while carrying out agribusiness operations. From the excerpt, it can also be inferred that appropriate technology could also be imported or produced by an entity outside the community in need of such technology.

A closer study of the excerpts revealed that appropriate technology should be carefully designed to suit the community's socioeconomic needs. In other words, it should 
not only help boost their livelihood, but it should also facilitate responsible living for the sustainability of the immediate environment. For the exam, specification equipment could be beneficial but harmful in the long run. Submission of the participants is consistent with the findings of several studies. For example, [28] indicated that an investor could fine-tune his process design so that an appropriate technology or novel approach to production is adopted as a way of creating a competitive advantage. According to [28], developing proper technology will fast-track production since the community needs such products and is limited by their inability to decipher the best way of getting them.

Development of appropriate technology, environmentally sustainable with no harm to the community, according to [43], will ensure continuity of business operation since the technology is harmless, will fast track business operation, and increase patronage. Inappropriate technology will incur the wrath of the community and the government of Ghana, culminating in the closure of such business operations or defined as illegal.

Due to their wealth of experience he agribusiness, the majority, $89 \%$ of the participants, was able to outline what they consider an effective strategy in adopting appropriate technology. Their responses are sentialptured in the excerpts below:

The firm's strategy considers the location where the business is located. For example, in Ghana, a strategy involving the use of fourth industrial revolution (4IR) technology such as artificial intelligence, Big Analytics, Advanced processes, or Augmented reality/wearables will be considered ineffective. Rather strategy employs materials readily available in Ghana and can be easily controlled by indigenes or employees.

Management staff in the $R \& D$ department with 8 years of working experience.

In developing an effective strategy, we first researched the recurring need that can be filled upon discovering the need, intense dialogue, and consultation of those within the sector. This helps us retrieve valuable information from those with firsthand details to convert such data into the formulation of appropriate technology to resolve the problem.

Non-management staff with six years of working experience in the $\mathrm{R} \& \mathrm{D}$ department.

\section{Discussions}

The excerpts above revealed that strategy in adopting appropriate technology and process design involves thorough research, consultation, and cognition of the environment within which the technology is to be adopted. Due to several limiting factors, especially low technological skills, the strategy should be simple, reproducible, and easy to operate. A complex or complicated approach to adopting technology could create difficult technology to maintain, support, or use.

Hence, as reflected in the excerpts, intelligent business leaders look for a realistic and straightforward strategy that will ensure a competitive edge and ensure continuity of the business operation. Such a process should be reproducible, employees can be trained, and partners and customers will be prone to accept it. Consultation with those experiencing the difficulty also paves the best strategy for adopting appropriate technology to boost competitive edge and value creation.

The findings of the study are consistent with the result of a study by [43] that whatever strategy is orchestrated, it should be suitable for the environment within which the business is located, easy to manage, prone to boosting competitive edge, and relevant in developing requisite skills or competencies in employees. Study in [44] tally with the result of this study, which intimated that strategy should be borne out of thorough consultation with those having firsthand information regarding the difficulty or constraints. The talk will also include possible recommendations by those experiencing the problem on how it can be resolved so that the 
development of appropriate technology by an investor will result in a competitive edge and continuity of the business operation since it will be a panacea to the problems or constraints associated with the sector.

Results of the study also coincide with the U-model, which indicated that strategy should be carefully developed through a pragmatic approach to ensure entry into an emerging market. The process entails four steps which respondents have mentioned. These include 1) acquisition of knowledge of the given market, 2) big commitment vital to decision making, 3) planned activities structured into stages, and 4) change or adapt to the market situation. This tally with the study result because consultation, strategy development, and adaptation to the market situation via the development of appropriate technology boost productivity and continuity.

One of the management staff with 10 years of working experience provided a practical example of a strategic move to adopt appropriate technology to fast-track entry into agribusiness. She stated:

We are interested in starting an agribusiness involved in the production of tomato paste. The arable land for the tomato plants, based on consultation, reveals that it is often affected by drought. We strategize to overcome the constraint. We developed an irrigation system with a touch of ingenuity. Smart sensor measuring the temperature of the ground was advantageous. As soon as this sensor detects a rise in temperature beyond a certain threshold, it triggers the pumping machine, allowing for irrigation. However, as soon as the temperature drops below a certain threshold, the pumping engine starts to stop pumping water. Hence, whether we are at the farm or not, there is constant water flow without flooding or lack of water.

Management staff with 11 years of working experience.
We process the coconut tree for its oil and water, thus requiring plucking a large quantity of the coconut fruit. Climbing the tree is very tedious; as a result, many of the laborers either charge too much or refrain from climbing. We got in touch with an engineer that designed and build an escalator/power ladder lift. All the raw material was procured in Ghana. With these power ladders, the difficulty of plucking the coconut was resolved, culminating in increased production and profit.

Gleaned from Focus Group 2.

Recently we opened a new branch, but we were confronted with drought due to poor weather conditions for growing cotton. As a result, the $R \& D$ department thoroughly investigated soil composition. In collaboration with our partner in Zimbabwe, who faced similar weather conditions and soil type, a drought-tolerant seed was engineered so that the cotton would grow and thrive with optimum yield irrespective of the level of water in the soil.

Management staff with 9 years of working experience.

A closer study of the excerpts above clearly demonstrated a novel approach or strategy to adopting innovative or appropriate technology. In all the instances, ample consultation, thorough observation of market condition, and development of a proper technology to resolve the constraint and ensure continuity in business operation. It is noteworthy that the technology was appropriate in each case because it fits the organizational environment and objectives. In each case, the technology was right because it was harmless to both the user and the environment. It is likewise appropriate because it fills the need of the business organization and eases the laborious work involved in putting on the pump from time to time, as well as climbing coconut trees without any safeguard. 
Table 1. Strategic ways to adopt Technology. Source: Research data

\begin{tabular}{|l|l|}
\hline Strategic ways to use Technology & Frequency of appearing in themes \\
\hline $\begin{array}{l}\text { Conduct in-depth enquiry and consultation so as to } \\
\text { decipher what is the need or what can make for } \\
\text { competitive advantage. }\end{array}$ & 7 \\
\hline $\begin{array}{l}\text { Decide whether to build or develop a technology to } \\
\text { fill the need or will purchase already made } \\
\text { technology }\end{array}$ & 4 \\
\hline $\begin{array}{l}\text { Make sure the strategy is sustainable, reproducible, } \\
\text { easy to maintain and is manufactured or purchased at } \\
\text { a relatively cheaper cost and }\end{array}$ & 8 \\
\hline
\end{tabular}

\section{Conclusion and Implications}

Strategic steps as indicated by participants: 1) Conduct in-depth enquiry and consultation so as to decipher what is the need or what can make for competitive advantage, 2) decide whether to build or develop a technology to fill the need or will purchase already made technology, 3) make sure the strategy is sustainable, reproducible, easy to maintain and is manufactured or purchase at a relatively cheaper cost and 4) be sure to make sure that the strategy suits your organizational culture and overall objective of the firm.

The following was also coded during the data compilation.

Table 2. Relative Benefits of Tech and Non-Tech Companies. Source: Research

\begin{tabular}{|l|l|l|}
\hline \multicolumn{3}{|l|}{ Relative Benefits of companies in an emerging economy (Ghana) } \\
\hline Tech-savvy companies & Traditional companies & For Both \\
\hline 4 & 2 & 2 \\
\hline Fast-tracked competitive Advantage & Low Maintenance cost & Tax holidays \\
\hline Increased productivity & short downtime & Relaxed policies \\
\hline Economies of scale & & \\
\hline Weak entry barriers & & \\
\hline
\end{tabular}

\section{Limitations of Studies}

Limited time and participants' availability due to the covid-19 impacts workers' shifts and outings. This was limited to the Agribusiness industry and hence cannot be generalized to other industries within the emerging market of Ghana.

Also, another empirical study could be conducted utilizing the quantitative approach to the research as this was biased towards qualitative approaches.

Many intended participants declined even after the promise of hiding their identity due to fear of their candid response going public and going against company policies.

\section{Conflict of Interest}

Moreover, no financial and relationship conflicts of interest exist. Therefore, the article is as balanced, objective, and evidence-based as possible.

\section{Acknowledgement}

Admittedly some assistance was received by some people into this manuscript (e.g., technically, writing and reading and editing service, general). However, the help does not mark authorship; hence there were no acknowledgments as co-authors. 


\section{References}

[1] Amankwah-Amoah et al.2020; (2014). Solar Energy in Sub-Saharan Africa: The Challenges and Opportunities of Technological Leapfrogging. Thunderbird International Business Review. 57. 10.1002/tie.21677.

https://www.researchgate.net/publication/268983770 _Solar_Energy_in_Sub-

Saharan_Africa_The_Challenges_and_Opportunities _of_Technological_Leapfrogging.

[2] Hoepner, A.G.F., Li, Q., Muzanenhamo, (2020) Penelope, Corporate Social Irresponsibility of African Firms Across the Continent: Does Leave the Path of Social Responsibility Hurt Shareholder Value? https://ssrn.com/abstract=3245952 or http://dx.doi.org/10.2139/ssrn.3245952.

[3] Adner, R., \& Kapoor, R. (2010). Value Creation in Innovation Ecosystems: How the Structure of Technological Interdependence Affects Firm Performance in New Technology Generations. Strategic Management Journal, 31 (3), 306-333. http://dx.doi.org/10.1002/smj.821.

[4] Balogun, J., \& Johnson, G. (2004). Organizational Restructuring and Middle Manager Sensemaking. The Academy of Management Journal, 47(4), 523-549. https://doi.org/10.2307/20159600.

[5] Sołoducho-Pelc, Letycja. (2014). Competitive Advantage: The Courage in Formulating Objectives and Expansiveness of a Strategy. Procedia - Social and Behavioral Sciences. 150. 271280.10.1016/j.sbspro.2014.09.058.

https://www.researchgate.net/publication/272392001 _Competitive_Advantage_The_Courage_in_Formul ating_Objectives_and_Expansiveness_of_a_Strategy

[6] Hakravarthy, B.S. (1986) Measuring Strategic Performance. Strategic Management Journal, 7,437458. https://doi.org/10.1002/smj.4250070505.

[7] Ramdani, B., Binsaif, A., Boukrami, E. (2019).

Business model innovation: a review and research agenda. New England Journal of Entrepreneurship. https://www.semanticscholar.org/paper/Businessmodel-innovation\%3A-a-review-and-researchRamdani-
Binsaif/618cf13429b7be3ab0c7346bd32ccf2541cb1 d3f.

[8] Ramdani B., Binsaif A., Boukrami E., Guermat C. (2020). Business models innovation in investment banks: a resilience perspective. Asia Pacific Journal of Management. 10.1007/s10490-020-09723-z. https://www.researchgate.net/publication/342245568 _Business_models_innovation_in_investment_banks _a_resilience_perspective\#pf8.

[9] Bstieler, L., Gruen, T., Akdeniz, B., Brick, D., Du, S., Guo, L., Khanlari, M., McIllroy, J., O’Hern, M., \& Yalcinkaya, G. (2018). Emerging Research Themes in Innovation and New Product Development: Insights from the 2017 PDMA-UNH Doctoral Consortium. Journal of Product Innovation Management, 35(3), 300-307. https://doi.org/10.1111/jpim.12447.

[10]Al-Debei, M. M., \& Avison, D. (2010). Developing a unified framework of the business model concept. European Journal of Information Systems, 19(3), 359-376. https://doi.org/10.1057/ejis.2010.21.

[11] Garcia, R., \& Calantone, R. (2002). A literature review is a critical look at technological innovation typology and innovativeness terminology. Journal of Product Innovation Management, 19(2), 110-132. https://doi.org/10.1111/1540-5885.1920110.

[12]Diaconu, Mihaela. (2011). Technological Innovation: Concept, Process, Typology, and Implications in the Economy. Theoretical and Applied Economics. XVIII (2011). 127-144. https://www.researchgate.net/publication/227364059 _Technological_Innovation_Concept_Process_Typo logy_and_Implications_in_the_Economy.

[13] Fagerberg, Jan. (2018). Innovation, Economic Development, and Policy. 10.4337/9781788110266. https://www.researchgate.net/publication/324891483 _Innovation_Economic_Development_and_Policy. [14]Fagerberg, J. (2013). Innovation - a New Guide. https://www.semanticscholar.org/paper/Innovationa-New-Guide-

Fagerberg/338e301677b9e2379449901cabc4c1ba8f $90 f 939$.

[15] José A. Pedraza-Rodríguez, Peter Bolcha, Luna Santos-Roldán. (2021) from strategies to innovation: 
an empirical study from Spain. Technology Analysis \& Strategic Management 33:2, pages 134-147.

[16] OECD/Eurostat (2018), Oslo Manual 2018: Guidelines for Collecting, Reporting and Using Data on Innovation, 4th Edition, The Measurement of Scientific, Technological and Innovation Activities, OECD Publishing, Paris/Eurostat, Luxembourg,

https://doi.org/10.1787/9789264304604-en.

[17]Chang, Victor, Wills, Gary and Baudier, Patricia (2021) Impacts and investigations of disruptive technologies for Industry 4.0. Technological Forecasting and Social Change. https://eprints.soton.ac.uk/cgi/request_doc?docid=22 34362.

[18] Mohibul, A.(2008)Internationalization Process of SME: Strategies and Methods https://www.divaportal.org/smash/get/diva2:121500/FULLTEXT01.p df.

[19] Sharma, D., \& Blomstermo, A., 2003. "The internationalization process of Born Globals: A network view," International Business Review, Vol. 12, pp. 739-753.

[20] Adner, R., \& Kapoor, R. (2009). Value Creation in Innovation Ecosystems: How the Structure of Technological Interdependence Affects Firm Performance in New Technology Generations (SSRN Scholarly Paper ID 1353582). Social Science Research Network. https://doi.org/10.2139/ssrn.1353582.

[21] Bstieler, L., Gruen, T., Akdeniz, B., Brick, D., Du, S., Guo, L., Khanlari, M., McIllroy, J., O’Hern, M., \& Yalcinkaya, G. (2018). Emerging Research Themes in Innovation and New Product Development: Insights from the 2017 PDMA-UNH Doctoral Consortium. Journal of Product Innovation Management, 35(3), 300-307. https://doi.org/10.1111/jpim.12447.

[22] Chowdhury, S., Azziz-Baumgartner, E., Kile, J. C., Hoque, Md. A., Rahman, M. Z., Hossain, Md. E., Ghosh, P. K., Ahmed, S. S. U., Kennedy, E. D., Sturm-Ramirez, K., \& Gurley, E. S. (2020). Association of Biosecurity and Hygiene Practices with Environmental Contamination with Influenza A Viruses in Live Bird Markets, Bangladesh.
Emerging Infectious Diseases, 26(9), 2087-2096. https://doi.org/10.3201/eid2609.191029.

[23] World Bank Group (2017). Leapfrogging: the key to Africa's development? From constraints to investment opportunities. Retrieved on March 2, 2020, from http://documents.worldbank.org/curated/en/1215815 05973379739/pdf/Leapfrogging-the-key-to-Africasdevelopment-from-constraints-to-investmentopportunities.pdf.

[24]Li, Shaomin, et al. "Corporate Social Responsibility in Emerging Markets: The Importance of the Governance Environment." MIR: Management International Review, vol. 50, no. 5, 2010, pp. 635-654. JSTOR, www.jstor.org/stable/41426815 Accessed 15 July 2021.

[25]Fagerberg, J., Martin, B. R., \& Andersen, E. S. (2013). Innovation Studies: Evolution and Future Challenges. Oxford University Press.

[26] World Bank. 2015. Big Data Solutions: Innovative Approaches to Overcoming Agricultural Challenges in Developing Nations by Harnessing the Power of Analytics. World Bank, Washington, DC. (C) World Bank. https://openknowledge.worldbank.org/handle/10986 /26436 License: CC BY 3.0 IGO

[27]Ball, V.E., Butault, J.P., Carlos, S.J.M. and Mora, R. (2010). Productivity and international competitiveness of agriculture in the European Union and the United States, Agricultural Economics 41, 611-627.

[28] Amankwah-Amoah, J., Debrah, Y. A., Yu, W., Adomako, S., \& Danso, A. (2020). Technology strategies in emerging economies: emerging issues, challenges, and new research. Elsevier B. $V$ : Technological Forecasting and Social Change, 2 (1), p. 1.

[29] Adner, R., \& Kapoor, R. (2009). Value Creation in Innovation Ecosystems: How the Structure of Technological Interdependence Affects Firm Performance in New Technology Generations (SSRN Scholarly Paper ID 1353582). Social Science Research Network.

https://doi.org/10.2139/ssrn.1353582. 
[30]Boso, N., Adeleye, I., Ibeh, K., \& Chizema, A. (2019). The internalization of African firms: opportunities, challenges, and risks. Thunderbird International Business Review, 61 (1), pp. 5-12.

[31] Abramovitz, M. 1956. Resource and output trends in the United States since 1870. American Economic Review, Papers, and Proceedings, 46 May: 5-23.

https://www.fao.org/3/x9447e/x9447e03.htm\#TopO fPage.

[32] Kothari (2004). Research methodology: Methods and Techniques. New Delhi; New age international $(P) \quad$ Limited, publisher http://www.sciepub.com/reference/233432.

[33] Kumar, R. (2011) Research Methodology: A Step-by-Step Guide for Beginners. 3rd Edition. Sage, New Delhi. https://www.scirp.org/(S(oyulxb452alnt1aej1nfow45 ))/reference/ReferencesPapers.aspx?ReferenceID=1 971596.

[34]Bonache, J. and Festing, M. (2020) 'Research paradigms in international human resource management: An epistemological systematization of the field,' German Journal of Human Resource Management, 34(2), pp. 99-123. Doi: $10.1177 / 2397002220909780$.

[35]Creswell, JW. 2014. Research Design: Qualitative, Quantitative, and Mixed Methods Approaches. Thousand Oaks: Sage Publications. https://www.scirp.org/(S(i43dyn45teexjx455qlt3d2q ))/reference/ReferencesPapers.aspx?ReferenceID $=1$ 964849.

[36] Creswell, JW. \& Poth, CN. (2018) Qualitative Inquiry and Research Design Choosing among Five Approaches. 4th Edition, Sage Publications, Inc., Thousand Oaks.

https://www.scirp.org/(S(lz5mqp453edsnp55rrgjct55 )$) /$ reference/reference papers.aspx ?referenceid=2155979.

[37] Yin, R.K. (2016). Qualitative Research from Start to Finish, Second Edition. New York: The Guilford Press. ISBN: 978-1-4625-1797-8. 386 pp. https://doi.org/10.1111/fcsr.12144.

[38]Lohfeld, W. (2008). Review: Sharlene HesseBiber \&amp; Patricia Leavy (2006). The Practice of Qualitative Research. Forum Qualitative
Sozialforschung Forum: Qualitative Social Research, 9(1). https://doi.org/10.17169/fqs-9.1.363. [39] Nyumba, T., Wilson, K., Derrick, C., \& Mukherjee, N., (2018) The use of focus group discussion methodology: Insights from two decades of application in conservation. Methods in Ecology and Evolution, 9(1), pp. 20-32.

[40] Overlien C, Aronsson K and Hyden M (2005) The focus group interview as an in-depth method? Young women are talking about sexuality. International Journal of Social Research Methodology $\quad$ 8(4): 331-344. https://journals.sagepub.com/doi/pdf/10.1177/00219 09619857098.

[41] Nowell, L.S., Norris, J.M., White, D.E. and Moules, N.J. (2017) Thematic Analysis: Striving to Meet the Trustworthiness Criteria. International Journal of Qualitative Methods, 16, 1-13. https://doi.org/10.1177/1609406917733847.

[42]Boso, N., Adeleye, I., Donbesuur, F., \& Gyensare, M. (2019). Do Entrepreneurs Always Benefit from Business Failure Experience? Journal of Business Research, 98, 370-379. https://doi.org/10.1016/j.jbusres.2018.01.063.

[43] Amankwah-Amoah J., Albert D., (2019), and Samuel A. "Entrepreneurial orientation, environmental sustainability, and new venture performance: Does stakeholder integration matter? "Business Strategy and the Environment 28.1: 7987.

https://onlinelibrary.wiley.com/doi/abs/10.1002/bse. 2191.

[44]Banjo R. (2021), Environmental sustainability engagement of firms: The roles of social capital, resources, and managerial, the entrepreneurial orientation of small and medium enterprises in Vietnam, Business Strategy, and the Environment, 10.1002/bse.2743, 30, 4, (2194-2208). 